Books, videos, CD-ROMs, DVDs and any other relevant items submitted for a review in the $B D J$ should be addressed to: Kate Maynard, Assistant Editor, British Dental Journal, NPG, 4-6 Crinan Street, London N1 9XW
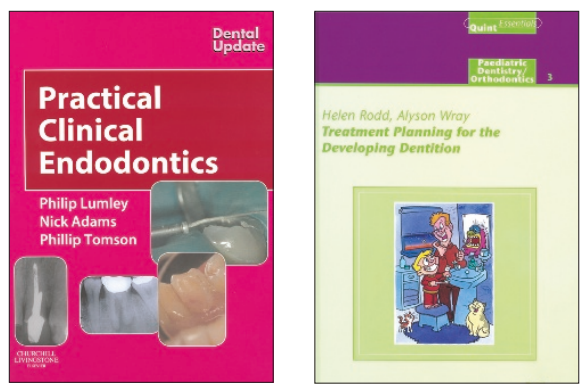

\section{Practical clinical endodontics}

P. Lumley, N. Adams, P. Tomson

UK: Elsevier

price $€ 39.99$, pp 109

ISBN 0443074828

This book is part of the Dental Update series, and is intended for primary care dentists, junior hospital dentists and dental students. It is a concise résumé of contemporary endodontics in 109 pages. It is profusely illustrated with radiographs, colour pictures and colour diagrams. These clearly demonstrate the clinical skills of the authors. Some of the radiographs have not reproduced well which will be a disappointment to the authors.

The structure of the book is sound, starting with the scientific basis, progressing through history and examination, covering root canal treatment in detail, considering root canal retreatment separately and concluding with surgical endodontics. For the busy practitioner the book provides the opportunity to update on current views in clinical endodontics. However, dental students although finding it useful for revision may wish to consult a more detailed source.

In view of the rapid changes in root canal instruments over the last decade, one can wonder whether some of the detailed technique described with specific rotary file systems might not become outdated rapidly. It is difficult for experienced practitioners brought up on hand instruments to let go, and embrace rotary instruments with enthusiasm. Although the authors recommend rotary instruments, they appear to do so rather cautiously.

It is good to see a chapter devoted to root canal retreatment. When treatment fails, it can usually be managed by retreatment rather than extraction or surgical endodontics. Specialists have gained particular expertise in root canal retreatment, and this book shows a range of problems that have been successfully managed by retreatment. As specialists spend relatively little time on surgical endodontics, the space devoted to the subject in this book seems more than necessary. It would be good to discourage junior hospital dentists from undertaking surgical endodontics, as the authors rightly point to the often poor outcome with traditional techniques. It is pleasing to see stress on the contemporary approach including the use of ultrasonic root-end preparation, but disappointing to see mention still of handpieces for root-end preparation, even if the authors have highlighted the risk of root perforation!

In summary this is a useful book for the busy practitioner, and the authors are to be congratulated.

T. R. Pitt Ford

\section{Treatment planning for the developing dentition}

\author{
H. Rodd, A. Wray \\ UK: Quintessence \\ price $€ 28$, pp 150 \\ ISBN 1850970815
}

Part of the Quintessential series, this book is aimed at general dental practitioners but is suitable for dental students. It covers treatment planning for the developing dentition in the practice setting. It is a colourfully illustrated text which is clearly laid out, making it easy to follow. The book is structured logically starting with a child's first visit, emphasising the importance of making the first dental encounter a positive experience.

The 'do's and don'ts' section in each chapter guides the clinician regarding common aspects of paediatric care, for example oral hygiene instruction, fluoride therapy and trauma management. Every clinician approaches local anaesthetic administration in paediatric patients with some trepidation. Therefore, I found the section on local anaesthetic administration extremely useful, especially phrases and terminology relevant for each age group eg describing the sensation of local anaesthetic once administered. The clinical scenarios in each chapter help the reader to put all the pieces together and visualise how the treatment planning principles are incorporated to manage examples of various clinical situations.

Each aspect of treatment in this book considers the possible orthodontic consequences of any action, for example, extraction of a first permanent molar or avulsion of a permanent maxillary central incisor. Restorative options for loss of a permanent maxillary incisor, such as an Essex retainer with an acrylic tooth to replace an avulsed tooth, are innovative as orthodontic space can be lost quickly. Perhaps this appliance could be used in cases of avulsion and luxation injuries to neighbouring teeth until a composite wire splint can be constructed. A fixed space maintainer fitted immediately postextraction is an original concept provided the patient is compliant and their oral hygiene is adequate.

The prevention chapter describes interim alternatives to etching fissure prior to fissure sealants, a handy alternative for high caries risk patients presenting with partially erupted first permanent molars. Available restorative materials are discussed in sequence describing their uses, properties and applications. Although the reader may be aware of the available materials, the applications for the child patient may vary in some respects, which I found helpful.

It is easy to maintain six monthly recall appointments for all patients. However, there is an insightful recall strategy section at the end of the book which guides the clinician on suitable recall periods for their patients. The time between recall visits depends on caries risk, age, and medical history with reference to the recent NICE guidelines available online.

This text is great as a quick reference in the practice or as a guide for 

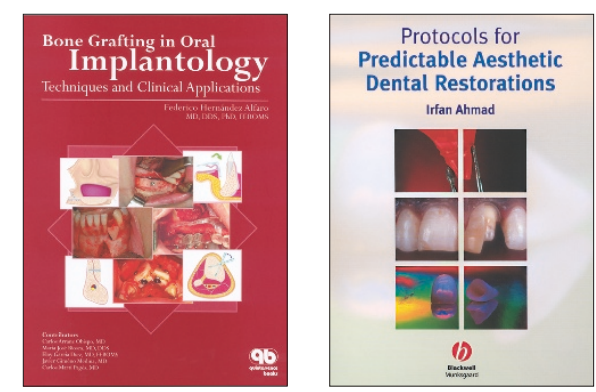

undergraduate studies, a useful addition to any dental library.

\section{E. Henley}

\section{Bone grafting in oral implantology: Techniques and clinical applications}

\author{
F. Hernández Alfaro \\ UK: Quintessence \\ price $\mathrm{E96.00,} \mathrm{pp} 234$ \\ ISBN 185097103X
}

As the scientific basis for provision of implant retained restorations continues to expand, we rely on practical advice of experienced clinicians to push the envelope of knowledge ever further. The author of this textbook advises that the stimulus for the text came from the desire of his postgraduate students to have a comprehensive manual for their daily practice. This book achieves that task in a very elegant manner. There are 11 chapters in the book, commencing with chapters on bone biology and general principles of bone grafting.

The first chapter begins, logically, with a paragraph titled 'Why bone grafts?' This sets the scene for a series of extensively illustrated chapters on bone grafting techniques. Some practical advice is given regarding choice of surgical instrumentation in Chapter 2, but this is not particularly detailed. The remaining nine chapters are divided into surgical procedures according to donor sites. Each of these chapters contains details of clinical applications, harvesting procedures and potential complications depending on the donor site.

Liberal use is made of high quality clinical photographs to illustrate clinical procedures and the text has the feel of a clinical atlas with its minimal reliance on text. Clinical images are supplemented throughout by schematic diagrams. In addition to describing the bone harvesting procedures, appropriate management of soft tissues is given due attention. This includes the need to use relieving incisions and split thickness pedicled flaps, as illustrated in Chapter 3. As the bulk of the material concerns large bony defects, few of the cases include the use of alloplastic bone graft materials. However, some of the cases describe the use of PRP and cancellous bone mixed with alloplastic materials.

In terms of bibliography, some of the chapters have a more detailed list of references than others, but this reflects the paucity of clinical research of some procedures. This text would have been enhanced by a dedicated chapter on treatment planning, inclusive of the necessity for the desired cosmetic result to drive the surgical process. Furthermore, it would have been nice to see more of the cases treated to completion.

However, these are only minor points which should not detract from the overall high quality of this textbook. It is a book written by a clinician for clinicians, and can be recommended to anyone with an interest in oral implantology and postgraduate trainees in surgery and prosthodontics.

F. Allen

\section{Protocols for predictable aesthetic dental restorations}

\author{
I. Ahmad \\ UK: Blackwell \\ price $€ 49.50$, pp 232 \\ ISBN 1405118202
}

This is a very attractive book, absolutely packed with the author's high quality colour photographs, some clinical and others artistic in their own right.

However, the title is misleading in that the book only concentrates on ceramic, chiefly extracoronal, restorations.

The author describes a "chronological clinical journey', starting with clinical assessment and treatment planning, including choice of ceramic system and colour and shade analysis. He then devotes individual chapters to successive stages in treatment to provide a crown for a tooth, such as core placement, tooth preparation, temporary restoration, impression taking, try-in and cementation. Very little attention is devoted to occlusal registration methods.

Although the liberal use of photographs makes this book extremely attractive to look at, the choice of illustrative cases is curious in places. Chapter 6, for instance, shows a case with widely spaced upper anterior teeth, where a reverse overjet is created orthodontically before crowns are constructed to close residual spacing. No clinical picture of the final result is presented, but judging by the illustrations which are provided, the width/length ratio of the final restorations does not appear particularly favourable.

Other photographs appear to have been included simply for the sake of including more colour pictures, and add nothing to the text. A photograph of a bottle labelled 'acetone', with the caption 'organic solvent: acetone', is one example of many.

There are some irritating typographical errors within the text. Worse still, there are some concepts with which I would take issue, for example in respect of classification of tooth discolouration. Despite the claim for evidence-basis for the principles described, I wonder how many of the references have actually been critically appraised before accepting their conclusions as unequivocally good quality evidence.

I would not recommend this book to undergraduate dental students whose budget is limited. For postgraduate students, I think its information could be obtained elsewhere in a more comprehensive and less personally biased form. 